\title{
Eicosapentaenoic acid and docosahexaenoic acid from fish oils: differential associations with lipid responses
}

\author{
Elizabeth C. Leigh-Firbank ${ }^{1}$, Anne M. Minihane ${ }^{1 *}$, David S. Leake ${ }^{2}$, John W. Wright ${ }^{3}$, \\ Margaret C. Murphy ${ }^{4}$, Bruce A. Griffin ${ }^{3}$ and Christine M. Williams ${ }^{1}$ \\ ${ }^{1}$ The Hugh Sinclair Unit of Human Nutrition, The University of Reading, Reading, UK \\ ${ }^{2}$ School of Animal and Microbial Sciences, The University of Reading, Reading, UK \\ ${ }^{3}$ The Centre for Nutrition and Food Safety, School of Biological Sciences, University of Surrey, Guildford, UK \\ ${ }^{4}$ European Institute of Health and Medical Sciences, University of Surrey, Guildford, UK
}

(Received 4 June 2001 - Revised 26 November 2001 - Accepted 21 December 2001)

\begin{abstract}
Fish-oil supplementation can reduce circulating triacylglycerol (TG) levels and cardiovascular risk. This study aimed to assess independent associations between changes in platelet eicosapentaenoic acid (EPA) and docosahexaenoic acid (DHA) and fasting and postprandial (PP) lipoprotein concentrations and LDL oxidation status, following fish-oil intervention. Fiftyfive mildly hypertriacylglycerolaemic (TG $1.5-4.0 \mathrm{mmol} / \mathrm{l}$ ) men completed a double-blind placebo controlled cross over study, where individuals consumed $6 \mathrm{~g}$ fish oil ( $3 \mathrm{~g}$ EPA + DHA) or $6 \mathrm{~g}$ olive oil (placebo)/d for two 6-week intervention periods, with a 12-week wash-out period in between. Fish-oil intervention resulted in a significant increase in the platelet phospholipid EPA $(+491 \%, P<0.001)$ and DHA $(+44 \%, P<0.001)$ content and a significant decrease in the arachidonic acid $(-10 \%, P<0.001)$ and $\gamma$-linolenic acid $(-24 \%, P<0.001)$ levels. A $30 \%$ increase in ex vivo LDL oxidation $(P<0 \cdot 001)$ was observed. In addition, fish oil resulted in a significant decrease in fasting and PP TG levels $(P<0 \cdot 001)$, PP non-esterified fatty acid (NEFA) levels, and in the percentage LDL as LDL-3 $(P=0.040)$, and an increase in LDLcholesterol $(P=0 \cdot 027)$. In multivariate analysis, changes in platelet phospholipid DHA emerged as being independently associated with the rise in LDL-cholesterol, accounting for $16 \%$ of the variability in this outcome measure $(P=0.030)$. In contrast, increases in platelet EPA were independently associated with the reductions in fasting $(P=0.046)$ and PP TG $(P=0.023)$, and PP NEFA $(P=0 \cdot 015)$, explaining $15-20 \%$ and $25 \%$ of the variability in response respectively. Increases in platelet EPA + DHA were independently and positively associated with the increase in LDL oxidation $(P=0 \cdot 011)$. EPA and DHA may have differential effects on plasma lipids in mildly hypertriacylglycerolaemic men.
\end{abstract}

Eicosapentaenoic acid: Docosahexaenoic acid: Triacylglyercol: Plasma lipid: Low-density lipoprotein oxidation

There is considerable evidence to support protective effects of the very-long-chain $n-3$ fatty acids against CHD (Burr et al. 1989; GISSI-Prevenzione Investigators, 1999). The dietary very-long-chain $n-3$ fatty acids eicosapentaenoic acid (EPA) and docosahexaenoic acid (DHA), found mainly in marine oils, have a range of biological activities which may attenuate both atherosclerosis and thrombosis. These include: beneficial effects on circulating lipoproteins; platelet, endothelial, neutrophil and monocyte cell functions; vascular compliance and blood pressure (Buttriss, 1999). Although their mechanisms of action are only partly understood, their influence on the degree of unsaturation of membrane phospholipids (and thereby membrane fluidity and function), together with regulatory effects on molecular events involved in lipid metabolism at the hepatic, adipose tissue and arterial intima level are now beginning to be elucidated. It was originally thought that both EPA and DHA had similar metabolic properties. However, recent evidence suggests that there are marked differences in the effects of the two fatty acids on the concentration and composition of plasma and membrane lipids.

\footnotetext{
Abbreviations: ALP, atherogenic lipoprotein phenotype; AUC, area under the curve; chol, cholesterol; DHA, docosahexaenoic acid; EPA, eicosapentaenoic acid; NEFA, non-esterified fatty acid; TG, triacylglycerol.

* Corresponding author: Dr Anne M. Minihane, fax +44 118 9310080, email minihane@ reading.ac.uk
} 
The ability of fish oils to reduce fasting triacylglycerol (TG) levels is well established, with $25 \%$ and $34 \%$ reductions reported in normolipidaemic and hyperlipidaemic groups respectively (Harris, 1997). Suppression of hepatic lipogenesis together with an increased hepatic mitochondrial oxidation of fatty acids, which result in reduced endogenous VLDL synthesis and secretion, are thought to be the primary mechanisms involved (Nestel et al. 1984; Harris, 1989; Kendrick \& Higgins, 1999). Animal (Willumsen et al. 1993; Berge et al. 1999) and in vitro (Wong et al. 1989) studies have suggested that EPA rather than DHA may be the hypotriacylglycerolaemic agent. However, divergent findings have been reported in studies of human subjects (Childs et al. 1990; Agren et al. 1996; Rambjør et al. 1996; Davidson et al. 1997; Mori et al. 2000a,b).

In addition to an effect on TG, supplementation with fish oil also influences characteristics of LDL that have been linked with atherogenesis, including susceptibility of LDL to oxidation, LDL particle size, as well as circulating LDL concentration. The replacement of dietary saturated fat with $n-6$ polyunsaturated fatty acids has been shown to increase the susceptibility of LDL to oxidation (Abbey et al. 1993; Reaven et al. 1993). A number of studies have also examined the impact of supplementing with an EPA + DHA preparation on LDL oxidation, with some studies observing increased susceptibility to oxidation (Suzukawa et al. 1995; Hau et al. 1996; Oostenbrug et al. 1997) and others observing no effect (Bonanome et al. 1996; Brude et al. 1997; Higgins et al. 2000). The variability in these findings may be attributable to a number of factors, which include: the degree of EPA + DHA supplementation; the $\alpha$-tocopherol content of the fish oils, which is often unreported; and the methods used to assess oxidative status. Limited results indicates a modest increase in LDL particle size following fish-oil intervention (Suzukawa et al. 1995; Mori et al. 2000a,b), a response which would be considered beneficial with respect to CHD risk. In addition, $n-3$ polyunsaturated fatty acid supplementation has also been shown to impact on overall LDL-cholesterol (Chol) concentration, with a 5-10\% increase commonly observed following fish-oil intervention (Harris, 1989, 1996; Suzukawa et al. 1995; Davidson et al. 1997). Davidson and co-workers reported that 0.0$2.5 \mathrm{~g} \mathrm{DHA} / \mathrm{d}$ increased LDL-chol concentration in a doserelated manner (Davidson et al. 1997). However, other studies have failed to observe an increase in LDL-chol following DHA feeding (Rambjør et al. 1996; Nelson et al. 1997).

In the present study we have examined the impact of fish-oil intervention on LDL oxidation, particle density and concentration in subjects with an atherogenic lipoprotein phenotype (ALP). This common proatherogenic profile, which is defined by moderately elevated fasting and postprandial TG, low HDL-chol and a predominance of the putatively atherogenic LDL-3, is associated with a 3-6-fold increase in CHD risk (Austin et al. 1988; Griffin et al. 1994). With platelet phospholipid fatty acid composition as a marker of responsiveness to EPA + DHA supplementation, we have used univariate and multivariate statistical analysis to assess the effects of increasing EPA and DHA, together and separately, on circulating lipoproteins. We have previously reported the overall responsiveness of this group to fish-oil supplementation as well as the impact of apolipoprotein E genotype (Minihane et al. $2000 a$ ).

\section{Materials and methods}

\section{Subjects}

The methods of recruiting and screening our ALP group has been described elsewhere (Griffin et al. 1999; Minihane et al. 2000a). In brief, the study group were recruited on the basis of a health and lifestyle questionnaire and a screening blood sample. Only individuals with an ALP lipid profile (fasting TG 1.5-4.0 mmol/l, HDL-chol $<1.1 \mathrm{mmol} / \mathrm{l}$, LDL-3 $>40 \%$ total LDL) were recruited. Further exclusion criteria for participation were as follows: diagnosed cardiovascular disease, liver disfunction, diabetes, smoking, blood pressure $>160 / 95 \mathrm{mmHg}$, haemoglobin $<130 \mathrm{~g} / \mathrm{l}$, BMI $>35 \mathrm{~kg} / \mathrm{m}^{2}$, or on hypolipidaemic therapy or any other medication known to interfere with lipid metabolism. The University of Reading and West Berkshire Health Authority Ethics Committees approved the study protocols and each individual gave their written consent.

\section{Study design}

The study was a double-blind placebo controlled crossover study where participants were randomly assigned to consume $6 \times 1 \mathrm{~g}$ capsules of fish oil (EPAX 5500TG; Pronova, Denmark) or $6 \mathrm{~g}$ olive oil (placebo; Pronova)/d for 6 weeks. The fish-oil supplement was approximately $50 \%$ EPA+DHA enriched, providing $279 \mathrm{mg}$ EPA and $223 \mathrm{mg}$ DHA/g oil. After a 12-week wash-out period individuals were crossed-over to receive the opposite supplementation regimen. Fasting blood samples were collected at 0,3 and 6 weeks of each supplementation period, and a postprandial assessment was carried out at the end of each intervention arm (6 weeks).

\section{Postprandial assessment}

Subjects underwent postprandial assessment following a $12 \mathrm{~h}$ overnight fast. No exercise or alcohol was allowed during the previous $24 \mathrm{~h}$, and in order to standardize short-term fat intake, a set evening meal, which contained $<20 \mathrm{~g}$ fat, was provided. On arrival at the Clinical Investigation Unit, an in-dwelling cannula was inserted into the antecubital vein of the forearm and a fasting blood sample taken. Following the test breakfast $(0 \mathrm{~min}, 50 \mathrm{~g}$ fat) and lunch (330 min, $30 \mathrm{~g}$ fat), blood samples were collected at $0,30,60,90,150,210,270,330,360,390$, 420 and $480 \mathrm{~min}$ to assess postprandial TG, glucose, insulin and non-esterified fatty acid (NEFA) responses. At $480 \mathrm{~min}, 100 \mathrm{IU}$ heparin/kg was administered intravenously, and a $5 \mathrm{ml}$ blood sample collected $15 \mathrm{~min}$ later in order to determine post-heparin lipoprotein lipase activity. 


\section{Biochemical analysis}

All blood samples were collected into $10 \mathrm{ml}$ potassium EDTA tubes, and $1 \mathrm{ml}$ fluoride oxalate tubes for the measurement of blood glucose. The samples were centrifuged at $1600 \mathrm{~g}$ for $10 \mathrm{~min}$ and the plasma stored at $-20^{\circ} \mathrm{C}$ for $\mathrm{TG}$, total chol, NEFA, glucose and insulin analysis and at $-80^{\circ} \mathrm{C}$ for plasma vitamin $\mathrm{E}$ analysis. For HDL-chol analysis a subsample of plasma was precipitated with dextran sulfate and magnesium chloride in order to remove apolipoprotein B-containing lipoproteins (McNamara et al. 1994), and the supernatant fraction stored at $-20^{\circ} \mathrm{C}$. LDL-chol was determined using the Friedewald formula (Friedewald \& Levi, 1972). Plasma collected for lipoprotein lipase activity was stored at $-80^{\circ} \mathrm{C}$ whilst the plasma $(10 \mathrm{ml})$ collected for LDL subclass distribution was stored at $4^{\circ} \mathrm{C}$ and analysed within $24 \mathrm{~h}$ of collection.

As previously described (Minihane et al. 2000a), plasma samples were analysed for TG, total chol, HDL-chol, glucose and NEFA using the Monarch Automatic Analyser (Instrumentation Laboratories Ltd, Warrington, Ches., UK), for LDL subclasses using density gradient ultracentrifugation (Griffin et al. 1990), for lipoprotein lipase activity using the ${ }^{3} \mathrm{H}$-labelled triolein technique (Nilsson-Ehle et al. 1980), and for insulin using a specific commercial ELISA kit (Dako Ltd, High Wycombe, Bucks., UK). The interand intra-assay $\mathrm{CV}$ for these techniques have been reported previously (Minihane et al. 2000b).

Postprandial TG responses were expressed as area under the curve (AUC) $(0-480 \mathrm{~min})$ or incremental AUC $(0-$ $480 \mathrm{~min}$ ), calculated using the trapezoidal rule. Due to the shape of the postprandial NEFA response, NEFA AUC $(0-480 \mathrm{~min})$ is difficult to interpret, with circulating NEFA concentrations dropping below baseline levels in the early postprandial period, therefore in the data analysis the NEFA postprandial response was represented as NEFA AUC (270-480 min).

Platelets were extracted from whole blood according to the method of Indu \& Ghafoorunissa (1992) (300 $g$ for $18 \mathrm{~min}$ followed by $1700 \mathrm{~g}$ for $10 \mathrm{~min})$, and stored at $-80^{\circ} \mathrm{C}$ for platelet phospholipid fatty acid analysis. Butylated hydroxytoluene was added to all solvents at a concentration of $50 \mathrm{mg} / \mathrm{l}$ to minimize auto-oxidation during lipid extraction and analysis. Phosphatidylethanolamine diheptadecanoic $(100 \mu \mathrm{l} ; 0.25 \mathrm{mg} / \mathrm{ml}$ chloroform) was added as internal standard to all samples. Lipids were extracted with chloroform-methanol (2:1, v/v) according to the method of Folch et al. (1957) and the phospholipid fraction isolated from the crude lipid using a Sep-Pack C18 column (Waters Associates, Milford, MA, USA) (Hamilton \& Comai, 1988). The phospholipids were transmethylated using sulfuric acid $(150 \mathrm{ml} / \mathrm{l}$ methanol), and the fatty acids quantified by GLC using a CPSil 88 column (Chrompak, Walton-on-Thames, Surrey, UK) (Indu \& Ghafoorunissa, 1992).

LDL was isolated from the platelet-poor plasma derived from the platelet isolation method described earlier. The platelet-poor plasma $(6 \mathrm{ml})$ was mixed by gentle inversion with $1.5 \mathrm{ml}$ sucrose solution $(500 \mathrm{~g} / \mathrm{l})$ and the mixture frozen at $-80{ }^{\circ} \mathrm{C}$ awaiting analysis. Upon thawing, the sucrose was removed by dialysing the sample using cellulose dialysis tubing $(6 \mathrm{~mm}$ diameter, $1 \mathrm{~mm}$ width, $0.32 \mathrm{~mm}$ thickness; Fischer Scientific, Loughborough, Leicester, UK) against phosphate buffer (0.14 M-NaCl, $1.9 \mathrm{mM}-\mathrm{NaH}_{2} \mathrm{PO}_{4}, \quad 8.1 \mathrm{mM}-\mathrm{Na}_{2} \mathrm{HPO}_{4}, \quad 100 \mu \mathrm{M}-\mathrm{Na}_{2}$ EDTA) for $12-15 \mathrm{~h}$, changing the buffer on three occasions. LDL was isolated from the plasma using a method adapted from Vieira et al. (1996). In brief, the density of the plasma was adjusted to $1.21 \mathrm{~g} / \mathrm{ml}$ with $\mathrm{KBr}$. The density-adjusted plasma $(3 \mathrm{ml})$ was overlaid with $1.006 \mathrm{~g} / \mathrm{ml}$ density solution in $8.9 \mathrm{ml}$ Beckman Optiseal polyallomer centrifuge tube and the solution centrifuged at $65000 \mathrm{rpm}$ for $3 \mathrm{~h}$ at $4^{\circ} \mathrm{C}$ in the Beckman $70 \cdot 1$ rotor (Beckman Coulter (UK) Ltd., High Wycombe, Bucks, UK). The orange band of LDL was extracted and further purified by adjusting the density of the LDL layer to $1.15 \mathrm{~g} / \mathrm{ml}$. The solution was overlaid with a $1.063 \mathrm{~g} / \mathrm{ml}$ density solution in a $13.5 \mathrm{ml}$ polycarbonate thick-walled centrifuge tube and the tubes centrifuged at $46000 \mathrm{rpm}$ for $16 \mathrm{~h}$ at $4^{\circ} \mathrm{C}$. LDL, which formed the top layer, was dialysed against 1.5-2.0 litres phosphate buffer in the presence of Chelex 100 (Bio-rad Laboratories Ltd., Hemel Hempstead, Herts., UK) for $24 \mathrm{~h}$, changing the buffer four times to remove the EDTA and $\mathrm{KBr}$.

LDL oxidation was assessed using a conjugated diene formation assay (Esterbauer et al. 1989). In this assay, the formation of conjugated dienes (breakdown products of lipid peroxidation) are monitored at $234 \mathrm{~nm}$. Lipid peroxidation in LDL $(50 \mu \mathrm{g} \mathrm{LDL}$ protein $/ \mathrm{ml})$ was induced by $\mathrm{CuSO}_{4}$, and the lag phase used as the primary index of the susceptibility of the LDL particle to oxidation. The lag phase was taken as the intercept of the tangent of the lag and propagation phases.

For $\alpha$-tocopherol analysis, $0 \cdot 5-1 \mathrm{ml}$ sodium dodecyl sulfate $(10 \mathrm{~mm})$ and $1 \mathrm{ml}$ ethanol, which containing $\alpha$-tocopherol acetate as internal standard, were added to $500 \mu \mathrm{l}$ plasma or $180 \mu \mathrm{g}$ LDL. Hexane $(2 \mathrm{ml})$ was added, the tube mixed for $5 \mathrm{~min}$ on a rotator and centrifuged at $2500 \mathrm{rpm}$ for $5 \mathrm{~min}$. This step was repeated three times. The hexane extracts were combined and evaporated under $\mathrm{N}_{2}$ and redissolved in $2 \mathrm{ml}$ hexane. The $\alpha$-tocopherol content of the extracts was analysed by HPLC using a Spherisorb $5 \mu \mathrm{m}$ analytical column $(250 \times 4.60 \mathrm{~mm}$; Phenomenex, Ches., UK), a hexane-isopropanol (99.25:0·75, $\mathrm{v} / \mathrm{v})$ mobile phase and fluorometric detection (excitation $290 \mathrm{~nm}$, emission $330 \mathrm{~nm}$ ) (American Oil Chemists' Society, 1990).

\section{Statistical analysis}

Group results are expressed as mean values with their standard errors. The data was checked for normality and skewed variables were log transformed prior to statistical analysis. The percentage change in the lipid outcome measures following supplementation was determined as: $\%$ changes $0-6$ week fish-oil $-\%$ change $0-6$ week olive-oil. The impact of fish-oil supplementation on fasting lipid levels in the overall group ( $n$ 55) was determined using two-way repeated measures ANOVA with time $(0,3,6$ weeks) and oil (fish oil, olive oil) as the independent variables. Post-treatment postprandial AUC and 
incremental AUC, and the fatty acid composition of platelet phospholipids at the end of each arm of the study were analysed using paired Student's $t$ tests. Linear associations between outcome measures were evaluated by testing Spearman's correlation coefficients and multiple linear regression analysis, with the change in serum lipids or LDL characteristics as the dependent variable and the change in platelet membrane phospholipids fatty acids, BMI and age as independent variables. Dependent variables were corrected for baseline levels prior to inclusion in the model. The validity of the regression model was monitored by the study of residuals $v$. predicted values. A $P$ value $<0.05$ was considered significant. All statistical analysis was performed using the SPSS statistical package (version 6.1; SPSS, Chicago, IL, USA).

\section{Results}

All fifty-five individuals completed the study. The responsiveness of a subgroup of these individuals for which apolipoprotein E genotype data was available has been previously reported (Minihane et al. 2000a). The baseline mean age, BMI, lipid and LPL activity of the group is shown in Table 1. No significant changes in body weight, background diet, alcohol consumption, or exercise or medication regimen was evident over the study period. The capsules, which provided $1.67 \mathrm{~g}$ EPA + $1.34 \mathrm{~g} \mathrm{DHA} / \mathrm{d}$, were well tolerated. Levels of platelet phospholipid EPA, DHA and arachidonic acid at the beginning of each arm of the study, indicated that the 12 week washout period was sufficient to reverse the metabolic effects of supplementation (results reported previously: Minihane et al. 2000a).

\section{Plasma lipids, glucose, insulin}

Fish-oil supplementation resulted in significant reductions of $33 \%(P<0.001), 23 \%(P<0.001)$ and $9 \%(P=0.002)$

Table 1. The baseline characteristics of the study group and the responsiveness to fish-oil intervention for 6 weeks*

(Mean values with their standard errors for fifty-five subjects)

\begin{tabular}{|c|c|c|c|c|c|}
\hline & \multicolumn{2}{|c|}{ Baseline } & \multicolumn{2}{|c|}{ Change $(\%)$} & \multirow[b]{2}{*}{$P+$} \\
\hline & Mean & SEM & Mean & SEM & \\
\hline Age (years) & 55 & 1 & NA & & NA \\
\hline $\mathrm{BMI}\left(\mathrm{kg} / \mathrm{m}^{2}\right)$ & $28 \cdot 0$ & 0.5 & 0.2 & 0.4 & 0.226 \\
\hline \multicolumn{6}{|l|}{ Fasting } \\
\hline Total chol (mmol/l) & $6 \cdot 60$ & $0 \cdot 11$ & -0.7 & $2 \cdot 0$ & 0.392 \\
\hline $\mathrm{TG}(\mathrm{mmol} / \mathrm{l})$ & 2.50 & 0.11 & $-33 \cdot 3$ & $5 \cdot 0$ & 0.000 \\
\hline HDL-chol (mmol/l) & 0.95 & 0.02 & -0.3 & $3 \cdot 2$ & 0.905 \\
\hline LDL-chol (mmol/l) & 4.53 & $0 \cdot 12$ & $7 \cdot 6$ & $3 \cdot 1$ & 0.027 \\
\hline LDL-chol:HDL-chol & 4.86 & 0.18 & $10 \cdot 3$ & 5.4 & 0.077 \\
\hline LDL-3 (\%)‡ & 62 & 3 & $-21 \cdot 1$ & $9 \cdot 3$ & 0.040 \\
\hline NEFA (umol/l) & 459 & 16 & -5.5 & $5 \cdot 0$ & 0.070 \\
\hline Glucose (mmol/l) & 5.49 & 0.09 & 3.3 & $2 \cdot 2$ & 0.233 \\
\hline Insulin $(\mathrm{pmol} / \mathrm{l})$ & 71.7 & $7 \cdot 0$ & -0.8 & $12 \cdot 0$ & 0.986 \\
\hline \multicolumn{6}{|l|}{ Postprandial } \\
\hline TG AUC§ & 1823 & 73 & $-22 \cdot 5$ & $2 \cdot 8$ & 0.000 \\
\hline TG incremental AUC\| & 525 & 33 & -9.0 & $5 \cdot 3$ & 0.002 \\
\hline Peak TGף & $5 \cdot 13$ & 0.22 & -20.9 & $2 \cdot 9$ & 0.000 \\
\hline Glucose AUC§ $\S^{\star \star}$ & 3277 & 48 & -1.6 & 0.9 & 0.023 \\
\hline Glucose incremental AUC $\|^{\star *}$ & 580 & 39 & -4.5 & $10 \cdot 6$ & 0.004 \\
\hline NEFA AUC (270-480 min)§†† & 111026 & 3704 & $-5 \cdot 4$ & $2 \cdot 6$ & 0.023 \\
\hline LPL (nmol FA/ml per min) 㧊 & 63 & 8 & $12 \cdot 8$ & $12 \cdot 4$ & 0.094 \\
\hline \multicolumn{6}{|l|}{ Fatty acids (mol/ $100 \mathrm{~mol}) \S \S$} \\
\hline $18: 2$ & $5 \cdot 78$ & $0 \cdot 19$ & & & \\
\hline $20: 4$ & $24 \cdot 31$ & 0.57 & & & \\
\hline $20: 5$ & 0.65 & 0.13 & & & \\
\hline $22: 6$ & 2.64 & 0.14 & & & \\
\hline
\end{tabular}

NA, not applicable; chol, cholesterol; TG, triacylglycerol; NEFA, non-esterified fatty acids; AUC, area under the curve; LPL, lipoprotein lipase; FA, fatty acid; 18:2, linoleic acid; 20:4, arachidonic acid; 20:5, eicosapentaenoic acid; 22:6, docosahexaenoic acid.

${ }^{*}$ For details of subjects, supplements and procedures, see p. 436.

†The statistical significance of the changes in fasting outcome variables were calculated using repeated-measures ANOVA with time and oil supplement (fish oil or olive oil) as the independent variables. The significance of changes in postprandial measurements were assessed using paired $t$ tests, or Wilcoxon signed rank test for nonnormally distributed data.

$\ddagger$ Small dense LDL.

$\S$ Calculated by the trapezoidal rule.

II Calculated as AUC minus the baseline value.

I Peak postprandial TG value (0-480 min).

${ }^{\star \star} \mathrm{mmol} / \mathrm{l}$ per $480 \mathrm{~min}$.

†† $\mu \mathrm{mol} / \mathrm{l}$ per $210 \mathrm{~min}$

执 15 min post-heparin LPL activity.

$\S \S$ Platelet membrane phospholipid fatty acid composition. 
in fasting TG, TG AUC and TG incremental AUC respectively (Table 1). For the group as a whole, little change in total chol or HDL-chol levels was evident following supplementation. However, there was a significant increase in circulating LDL-chol $(+8 \%, P=0.027)$ but a significant reduction in the percentage of LDL as LDL-3 (-21\%, $P=0.040)$ was also evident. The $10 \%$ increase in LDLchol:HDL-chol: reached borderline significance $(P=$ 0.077). The intervention regimen had little impact on fasting or postprandial (results not shown) insulin or fasting glucose levels. However, significant decreases in glucose AUC $(P=0.023)$ and glucose incremental AUC $(P=0.004)$ were observed, suggesting improvements in insulin sensitivity. There was a trend towards a reduction in circulating NEFA levels by fish oils throughout the postprandial period, with a $5 \%(P=0.023)$ decrease in the late postprandial period (270-480 min) (Fig. 1). Due to large inter-individual variability in responsiveness, the $13 \%$ increase in mean post-heparin lipoprotein lipase activity failed to reach significance $(P=0 \cdot 094)$.

\section{Platelet membrane phospholipid fatty acid composition}

Figure 2 shows the change mol/100 mol in platelet phospholipid fatty acid composition from $0-6$ weeks on the placebo (olive oil) and fish-oil supplements ( $n$ 21). No significant changes in linoleic acid (LA) $(P=0.663), \gamma$-LA $(P=0.793)$, arachidonic acid $(P=0.490)$, EPA $(P=0.207)$, or DHA $(P=0.394)$ levels were evident following oliveoil supplementation. Fish-oil supplementation resulted in a significant $24 \%(P<0.001)$ decrease in the $\gamma$-LA content from 1.92 to $1.45 \mathrm{~mol} / 100 \mathrm{~mol}$, and a $10 \%(P<0.001)$ decrease in arachidonic acid from 24.10 to $21.71 \mathrm{~mol} /$ $100 \mathrm{~mol}(P<0 \cdot 001)$. Highly significant increases in the EPA and DHA content of the platelet membrane were

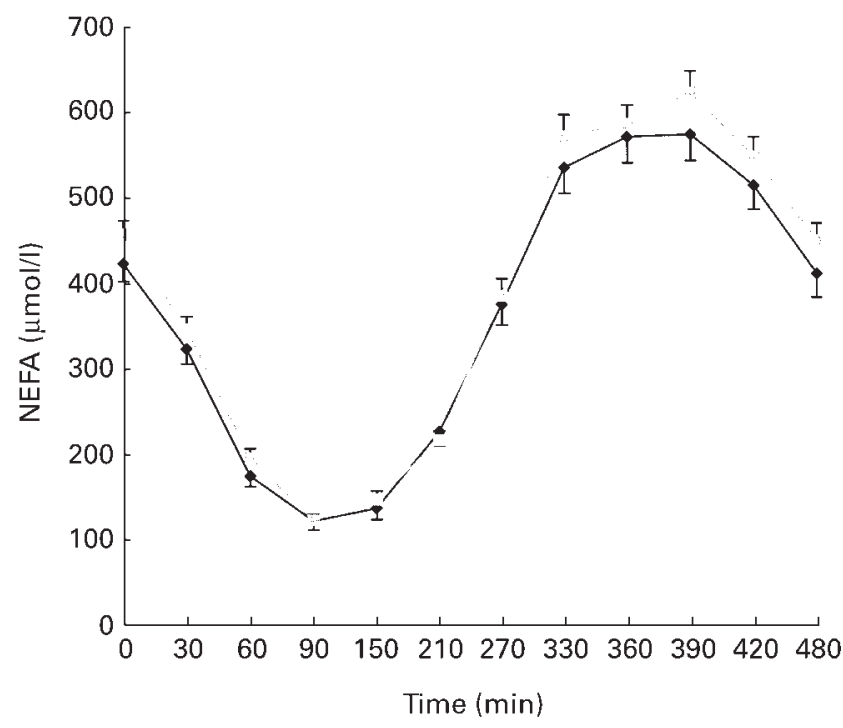

Fig. 1. Responsiveness of non-esterified fatty acids (NEFA) to test meals following $6 \mathrm{~g}$ fish-oil or olive-oil/d for 6 weeks $\bullet$, Fish oil; $\mathbf{\square}$, placebo. For details of subjects, supplements and procedures, see p. 436 . Breakfast was given at $0 \mathrm{~min}$ and lunch at $330 \mathrm{~min}$. Values are means for fifty-five subjects with standard errors shown by vertical bars. observed following fish-oil intervention. EPA levels increased 5-fold $(P<0.001)$, from 0.53 to $3.13 \mathrm{~mol} /$ $100 \mathrm{~mol}$, whilst DHA levels increased by $44 \%$ from 2.50 to $3.61 \mathrm{~mol} / 100 \mathrm{~mol}(P<0 \cdot 001)$.

\section{LDL oxidation}

Mean values for the lag times before initiation of conjugated diene formation and LDL oxidation for the placebo and fish-oil periods are shown in Fig. 3. A $30 \%$ reduction of the lag phase occurred after 3 weeks of fish-oil supplementation (71.2 (SEM 2.2) to 49.7 (SEM 2.2) min), which was sustained at 6 weeks (51.6 (SEM 1.5) min) $(P<0 \cdot 001)$. The lag phase after 3 weeks on the placebo phase was similar to that at time zero (68.2 (SEM 1.6) min v. 71.1 (SEM 2.2) min respectively, $(P=0.064))$, but the mean increase of $6.9 \mathrm{~min}$ by week 6 was statistically significant $(P=0 \cdot 008)$.

\section{Plasma and LDL Vitamin E composition}

Figure 4 gives the group mean changes in plasma and LDL $\alpha$-tocopherol levels. An increase in plasma $\alpha$-tocopherol from 15.5 (SEM 2.6) to 19.5 (SEM 2.3) $\mu \mathrm{mol} / 1(P=0.027)$ and LDL $\alpha$-tocopherol from 8.3 (SEM 0.8) to 9.4 (SEM 1.2) $\mathrm{nmol} / \mathrm{mg}$ LDL protein (NS) was evident following olive-oil supplementation. On the fish-oil treatment the changes in plasma $\alpha$-tocopherol from 19.8 (SEM 1.0) to 19.6 (SEM 1.0) $\mu \mathrm{mol} / 1$ and LDL $\alpha$-tocopherol from $10 \cdot 1$ (SEM 1.4) to 9.1 (SEM 1.1) nmol/mg LDL following 6 weeks of supplementation were not significant. Using repeated-measures ANOVA no treatment effect over time on plasma or LDL $\alpha$-tocopherol levels was evident.

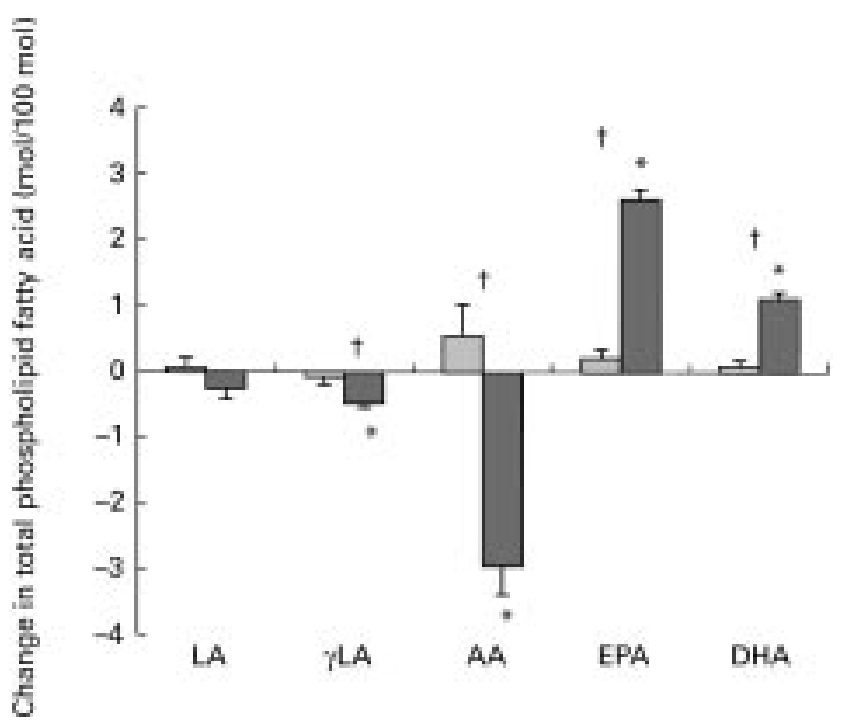

Fig. 2. Changes in platelet phospholipid fatty acid from baseline to the end of each intervention period ( 6 weeks) in the fish-oil and oliveoil phases ( $n$ 21). $\mathbf{n}$, Olive oil; $\mathbf{\square}$, fish oil. LA, linoleic acid; $\gamma \mathrm{LA}$, gamma-linoleic acid; AA, arachidonic acid; EPA, eicosapentaenoic acid; DHA, docosahexaenoic acid. For details of subjects, supplements and procedures, see p. 436. Values are means with standard errors shown by vertical bars. Mean values were significantly different from those of the control group: ${ }^{*} P<0.05$ Overall treatment effects were significant: $† P<0.05$ (repeated-measures ANOVA). 


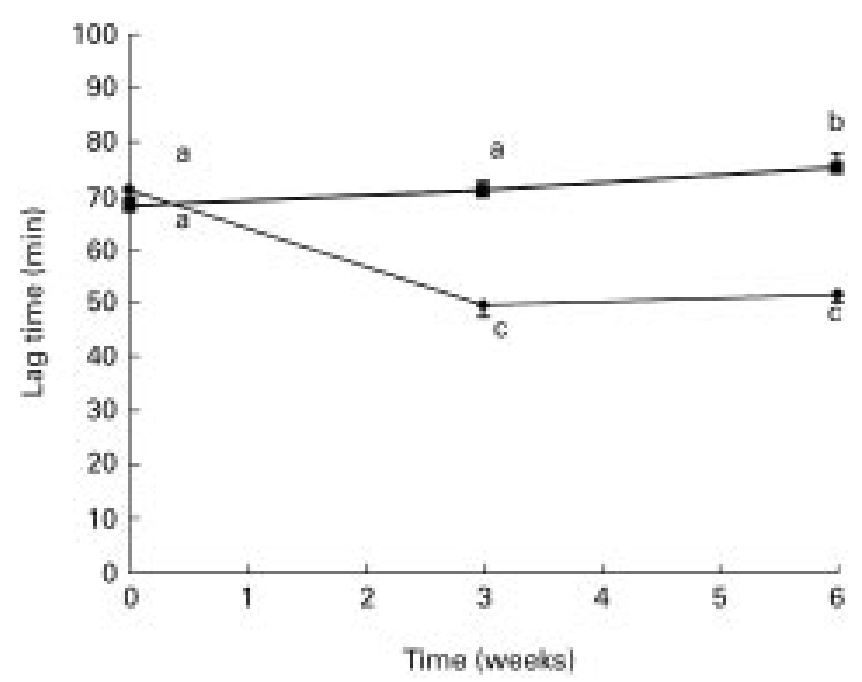

Fig. 3. The effect of dietary supplementation of $6 \mathrm{~g}$ fish oil or olive oil/d for 6 weeks on LDL oxidation, measured as the lag phase of conjugated diene formation by copper. $\bullet$, Fish oil, $\mathbf{\square}$, olive oil. For details of subjects, supplements and procedures, see p. 436. Values are means for fifty-five subjects with standard errors shown by vertical bars. Statistical significance of the group changes was calculated using repeated-measures ANOVA, with time and oil supplement as the independent variables. ${ }^{a, b, c}$ Mean values with unlike superscript letters were significantly different $(P<0.05)$.

Correlation between changes in platelet phospholipid fatty acid composition and plasma lipid and lipoprotein levels

A significant correlation between the fall in fasting TG $(r-0.462, P=0.035)$ and TG AUC $(r-0.453, P=0.045)$ and the increase in the platelet content of EPA was observed (Table 2). Little association between changes in LA, $\gamma$-LA, arachidonic acid or DHA and fasting or postprandial TG responses were evident. However, the change in platelet DHA was positively associated with the observed increases in LDL-chol $(r$ 0.699, $P<0.001)$.
No significant associations between the modest changes in total chol $(-0.7 \%$, Table 2$)$ and HDL-chol $(-0.3 \%$, Table 2) and any post-supplementation fatty acid changes were observed. The decrease in fasting NEFA levels was modestly, but not significantly correlated with the increase in platelet DHA $(r-0 \cdot 391, P=0.088)$, whilst the decrease in NEFA levels in the late postprandial period (NEFA AUC 270-480 min) was negatively correlated with the changes in platelet EPA $(P-0 \cdot 570, P=0 \cdot 009)$. No significant association between EPA or DHA changes and glucose responsiveness was evident. Significant univariate correlation's between the increases in both EPA $(P$ 0.042) and DHA $(P$ 0.027) and the increase in LDL oxidizability were evident.

\section{Multiple regression analysis}

Multiple regression analysis was used to establish the independence of the associations observed in the univariate correlation analysis. The results are given in Table 3 . The change in DHA $(P=0.030)$ but not EPA $(P=0.293)$, emerged as an independent determinant of the rise in LDL-chol, accounting for $16 \%$ of the variability in this outcome measure. Changes in platelet phospholipid EPA were independently associated with the decrease in fasting TG $(P=0 \cdot 046)$, TG AUC $(P=0 \cdot 023)$ and peak postprandial TG $(P=0.027)$, and explained $15-20 \%$ of the variability of the changes in these variables. The enrichment of platelet EPA was also an independent determinant of the reductions in circulating NEFA levels in the late postprandial period (NEFA AUC (270-480 min), $P=0.015)$, with the increase in platelet EPA being associated with a reduction in circulating NEFA. Neither EPA nor DHA emerged as independent determinants of the post-supplementation increase in LDL oxidizability. Due to multicolinearity of the variables EPA, DHA and total $n-3$ $($ EPA + DHA), changes cannot be included in the same
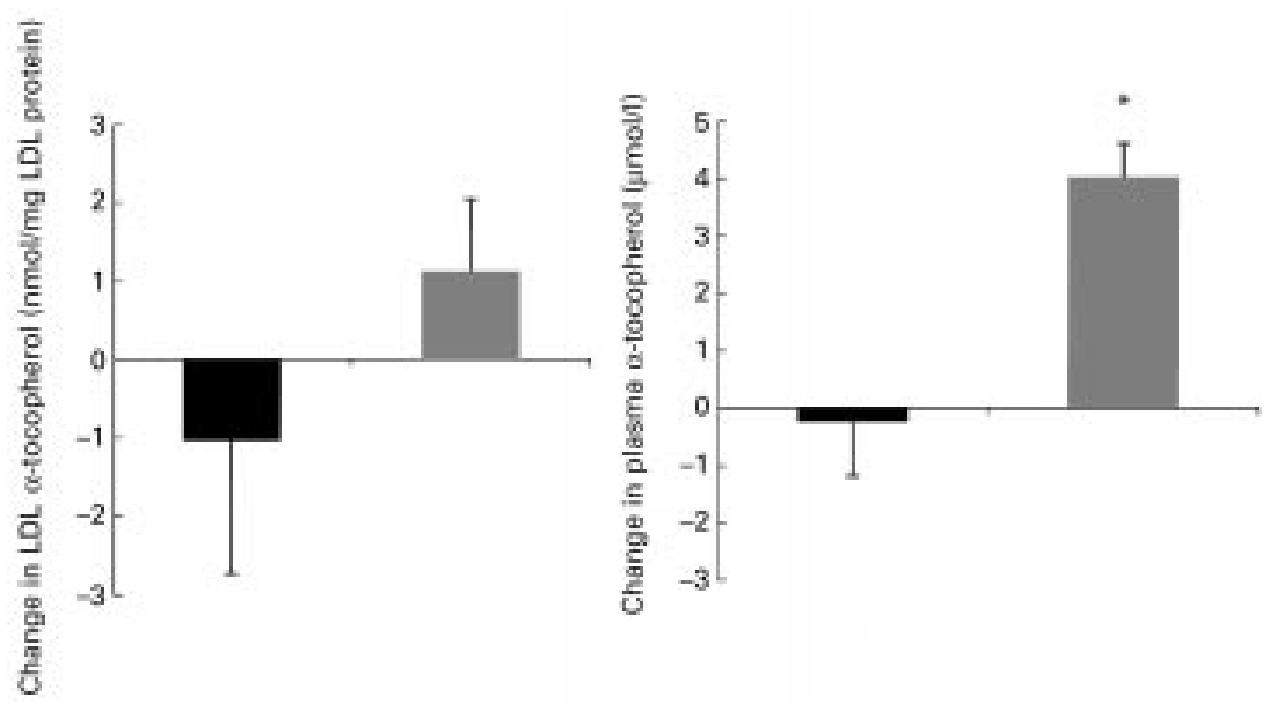

Fig. 4. Changes in the $\alpha$-tocopherol content of LDL and plasma following the consumption of $6 \mathrm{~g}$ olive oil or $6 \mathrm{~g}$ fish oil/d for 6 weeks. $\square$, Olive oil; $\mathbf{a}$, fish oil. For details of subjects, supplements and procedures, see p. 436 . Values are means with standard errors shown by vertical bars. Mean value was significantly different from baseline value: ${ }^{*} P<0 \cdot 027$. 
Table 2. Correlation coefficients $(r)$ between absolute changes in fatty acid composition and changes in lipid outcome measures following supplementation of fifty-five subjects, with fish oil for 6 weeks§॥ (spearmans bivariate correlation coefficients)

\begin{tabular}{|c|c|c|c|c|c|}
\hline \multirow[b]{2}{*}{ Change in... } & \multicolumn{5}{|c|}{ Fatty acid } \\
\hline & c18:2 & c20:3 & c20:4 & c20:5 & C22:6 \\
\hline Total chol & 0.142 & 0.112 & -0.029 & -0.235 & 0.365 \\
\hline LDL-chol & 0.327 & 0.207 & -0.144 & 0.083 & $0.699^{* * *}$ \\
\hline HDL-chol & -0.044 & -0.107 & 0.221 & -0.048 & -0.099 \\
\hline Fasting TG & -0.062 & -0.114 & 0.134 & $-0.462^{\star}$ & -0.215 \\
\hline TG AǓCף & 0.084 & -0.055 & 0.029 & $-0.453^{*}$ & -0.149 \\
\hline TG incremental AUC ${ }^{\star \star}$ & 0.232 & 0.187 & -0.004 & -0.317 & -0.027 \\
\hline Peak TG†† & 0.199 & 0.005 & 0.067 & $-0.403 \S$ & -0.071 \\
\hline LDL-3 (\%) 㧊 & $0 \cdot 177$ & 0.138 & $0 \cdot 120$ & 0.037 & 0.116 \\
\hline LDLox & -0.212 & 0.112 & 0.068 & $-0.447^{\star}$ & $-0.483^{\star}$ \\
\hline Fasting NEFA & $-0.464^{*}$ & -0.284 & 0.023 & -0.147 & $-0.391 \ddagger$ \\
\hline NEFA AUC (270-480 min)ף §§ & 0.021 & 0.202 & 0.114 & $-0.570^{\star *}$ & -0.152 \\
\hline
\end{tabular}

18:2, linoleic acid; 20:3, $\gamma$-linolenic acid; 20:4, arachidonic acid; 20:5, eicosapentaenoic acid; 22:6, docosahexaenoic acid; chol, cholesterol; TG, triacylglycerol; AUC, area under the curve; LDLox, Cu-induced oxidation of LDL; NEFA, non-esterified fatty acids.

${ }^{\star} P<0.05,{ }^{\star \star} P<0.01,{ }^{\star \star \star} P<0.001$

$\dagger P=0.078, \ddagger P=0.088$.

$\S$ For details of subjects, supplements and procedures, see p. 436.

$\|$ Absolute changes $=$ fish oil (week 6$)$ - olive oil (week 6).

ๆ Calculated by the trapezoidal rule.

${ }^{* *}$ Calculated as AUC minus the baseline value.

†† Peak postprandial TG value (0-480 min).

持mall dense LDL.

$\S \S \mu \mathrm{mol} / /$ per $210 \mathrm{~min}$.

regression model. However when total $n-3$ was added as a variable as opposed to EPA or DHA, it emerged as an independent determinant of the increases in LDL oxidizability $(P=0 \cdot 011$, results not shown)

\section{Discussion}

The purpose of the present study was to examine the effects of fish-oil supplementation on LDL oxidizability, density and concentration, as each of these variables are key determinants of atherogenesis. In addition, using statistical analysis, associations between EPA and DHA changes following fish-oil supplementation and lipid and lipoprotein changes were examined in order to establish which of the two fatty acids is associated with alterations in lipoprotein metabolism.

In the current study, fish oils, providing $1.67 \mathrm{~g}$ $\mathrm{EPA}+1.34 \mathrm{~g} \mathrm{DHA} / \mathrm{d}$, resulted in 491 and $44 \%$ increases in the platelet phospholipid content of EPA and DHA respectively. Other investigators have reported comparable changes in fatty acid composition (Sanders \& Roshanai, 1983). As has been previously observed, greater increases in membrane phospholipid levels relative to intake were evident for EPA compared with DHA (Sanders \& Roshanai, 1983; Vidgren et al. 1997; Zuijdgeest-van Leeuwen et al. 1999). This may be attributable to a number of factors including: higher baseline DHA levels, selective postabsorptive oxidation of DHA; selective release of DHA from membranes; retroconversion of DHA to EPA; or reduced conversion of EPA to DHA due to the known inhibitory effect of EPA on $\Delta^{6}$ - desaturase (Von Schacky \& Weber, 1985; Voss et al. 1991; Conquer \& Holub, 1997).

The efficacy of EPA + DHA intervention in counteract- ing the dyslipidaemia of the ALP and the possible mechanisms involved has been discussed previously (Minihane et al. 2000a). In brief, supplementation with $6 \mathrm{~g}$ fish-oil/d providing $3 \mathrm{~g} \mathrm{EPA}+\mathrm{DHA}$ resulted in significant reductions in fasting and postprandial TG responses, and in the percentage of LDL as LDL-3, effects which could be considered as beneficial with respect to CHD risk. However, a significant increase in LDL-chol and LDL oxidizability was also evident, both of which can be considered as potential adverse consequences of fish-oil intervention in terms of cardiovascular risk.

Although it was previously thought that EPA and DHA have comparable effects on lipid metabolism, it is now recognized that there may be discernible differences in the effects of these fatty acids on plasma and membrane lipids. In addition, they have also been shown to have different effects on endothelial function (Mori et al. $2000 b$ ). Knowledge of the relative actions and potencies of these fatty acids has a wide practical importance, as such information could be used to design mixtures of variable EPA + DHA content, tailored according to the baseline lipid status of the individual, and use selectively in order to ensure maximum benefit.

In agreement with previous studies, an $8 \%$ increase in circulating LDL-chol levels was evident following fishoil supplementation (Hughes et al. 1990; Harris, 1996). Using correlative $(r 0.699, P<0.001)$ and multivariate statistics $(P=0.030)$, it was observed that changes in membrane phospholipid DHA content were independently associated with the increase in the LDL-chol fraction in the present study. Davidson and co-workers observed increases in LDL-chol of $9 \%$ (NS) and $14 \%(P<0.001)$ following supplementation with $1.25 \mathrm{~g}$ and $2.5 \mathrm{~g} \mathrm{DHA} / \mathrm{d}$ 
Table 3. Multiple linear regression analysis of changes in platelet lipids as dependent variables with changes in plasma phospholipid eicosapentaenoic and docosahexaenoic acid as independent variables* $\dagger$

\begin{tabular}{|c|c|c|}
\hline & $\Delta$ EPA & $\Delta \mathrm{DHA}$ \\
\hline \multicolumn{3}{|l|}{$\Delta$ LDL-chol } \\
\hline Coefficient (SEM) & $-0.230(0.211)$ & $0.754(0.319)$ \\
\hline Adjusted model $R^{2}$ & & 0.159 \\
\hline$P$ & 0.293 & 0.030 \\
\hline \multicolumn{3}{|l|}{$\Delta$ LDLox } \\
\hline Coefficient (SEM) & $-5 \cdot 2(-0.3)$ & $-9.5(5.8)$ \\
\hline \multicolumn{3}{|l|}{ Adjusted model $R^{2}$} \\
\hline$P$ & 0.188 & 0.116 \\
\hline \multicolumn{3}{|l|}{$\Delta$ Fasting TG } \\
\hline Coefficient (SEM) & $-0.748(0.349)$ & $0.014(0.531)$ \\
\hline Adjusted model $R^{2}$ & 0.150 & \\
\hline$P$ & 0.046 & 0.978 \\
\hline \multicolumn{3}{|l|}{$\Delta$ TG AUC $\ddagger$} \\
\hline Coefficient (SEM) & $-498(199)$ & $157(301)$ \\
\hline Adjusted model $R^{2}$ & 0.194 & \\
\hline$P$ & 0.023 & 0.609 \\
\hline \multicolumn{3}{|l|}{$\Delta$ TG incremental AUC§ } \\
\hline Coefficient (SEM) & $-131(88)$ & $140(133)$ \\
\hline Adjusted model $R^{2}$ & & \\
\hline$P$ & 0.155 & 0.304 \\
\hline \multicolumn{3}{|l|}{$\Delta$ Peak TG $(0-480 \mathrm{~min})$} \\
\hline Coefficient (SEM) & $-1.38(0.57)$ & $0.634(0.861)$ \\
\hline Adjusted model $R^{2}$ & 0.171 & \\
\hline$P$ & 0.027 & 0.471 \\
\hline \multicolumn{3}{|l|}{$\Delta$ Fasting NEFA } \\
\hline $\begin{array}{l}\text { Coefficient (SEM) } \\
\text { Adiusted model } R^{2}\end{array}$ & $-7 \cdot 36(31 \cdot 81)$ & $-86.99(48.01)$ \\
\hline$P$ & 0.820 & 0.088 \\
\hline \multicolumn{3}{|c|}{$\Delta$ NEFA AUC (270-480 min) $\ddagger \|$} \\
\hline Coefficient (SEM) & $-29512(10890)$ & $5175(16434)$ \\
\hline Adjusted model $R^{2}$ & 0.246 & \\
\hline$P$ & 0.015 & 0.757 \\
\hline \multicolumn{3}{|c|}{$\begin{array}{l}\text { EPA, eicosapentaenoic acid; DHA, docosahexaenoic acid; chol, cholesterol; LDLox, Cu-induced oxidation of LDL; TG, } \\
\text { triacylglycerol; AUC, area under the curve; NEFA, non-esterified fatty acid. } \\
\text { *For details of subject and procedures, see p. } 436 \text {. } \\
\text { †A negative coefficient indicates an inverse relation. }\end{array}$} \\
\hline
\end{tabular}

respectively for a 6-week period to patients with combined hyperlipidaemia (Davidson et al. 1997). The LDL-chol changes were highly correlated $(r$ 0.94, $P<0.001)$ with the increase in plasma phospholipid DHA (Davidson et al. 1997; Hughes et al. 1990). These findings were confirmed by Mori et al. (2000a) who recorded an $8 \%$ increase in LDL-chol following supplementation with $4 \mathrm{~g}$ purified DHA for 6 weeks. This increase in LDL-chol associated with increased DHA intake may result from a number of mechanisms including: greater conversion of DHA-enriched VLDL to LDL; an impact of DHA enrichment of the hepatocyte on the orientation of the LDL receptor; or an impact of DHA enrichment of LDL on its physio-chemical properties and interaction with the LDL receptor. In addition DHA may impact on LDL-chol at the nuclear level by influencing the expression of key genes involved in LDL metabolism. Further work is needed to examine these possibilities. Despite the apparent concordance of our own findings with those of others, an increase in LDL-chol following DHA intervention is not a universal finding (Rambjør et al. 1996; Nelson et al. 1997).
This apparently adverse effect of fish-oil intervention on LDL-chol may be counteracted by the $21 \%$ decrease in the percentage of LDL as the small dense LDL-3, which represents a shift towards a larger, less atherogenic LDL particle. However, in contrast to the findings of Mori et al. $(2000 a)$, little association between membrane fatty acid changes and changes in LDL density were evident in the present study. Results from our own (Minihane et al. 2000b) and other studies (Suzukawa et al. 1995) have indicated that circulating TG are a primary determinant of LDL-3 levels, with fasting TG shown to explain $47 \%$ of the variability in the percentage of LDL as LDL-3 (Minihane et al. 2000b). In the present study it is likely, therefore, that it is the reduction in TG levels rather than any fatty acid changes which results in the shift in LDL subclass distribution.

Uncertainties regarding the possible adverse effects of fish-oil intervention on the susceptibility of the LDL particle to oxidation is a major concern when recommending the use of fish oils as an anti-atherogenic agent. This is of particular concern in individuals with an ALP, in whom a predominance of the small dense LDL-3 particle, 
which is putatively more susceptible to oxidation (DeGraaf et al. 1991), is a defining feature. Although it remains controversial whether or not LDL oxidizability is a significant determinant of CHD risk (Regnstrom et al. 1992; Andrews et al. 1995; Toshima et al. 2000), many consider oxidized LDL to be important in the initiation and progression of atherogenesis (Berliner et al. 1990; Weis et al. 1991; Steinberg, 1997; Holvoet \& Collen, 1998). Several studies have investigated the effect of altering the fat composition of the diet on LDL oxidation. An increase in linoleic acid ( $n-6$ polyunsaturated fatty acid) has repeatedly been shown to result in an increase in ex vivo oxidation and macrophage degradation of LDL, relative to a comparable oleic acid-rich diet (Abbey et al. 1993; Reaven et al. 1993). In addition, and in agreement with the findings of the current study, a number of investigators have reported an adverse affect of fish oil ( $n-3$ polyunsaturated fatty acid) supplementation on LDL oxidation (Harats et al. 1991; Abbey et al. 1993; Reaven et al. 1993; Suzukawa et al. 1995; Mata et al. 1996). Following consumption of fish oils providing $3.4 \mathrm{~g}$ EPA + DHA/d for 6 weeks, Suzukawa et al. (1995) observed a significant $26 \%$ reduction in the lag time before rapid oxidation of LDL by $\mathrm{Cu}$ commenced. In the present study, where fish-oil intervention provided $3 \mathrm{~g} \mathrm{EPA}+\mathrm{DHA} / \mathrm{d}$ for 6 weeks, a comparable $28 \%$ reduction in lag time was observed. Correlation and regression analysis indicated that an increase in both the EPA and DHA status was associated with the observed increase in LDL oxidation.

The level of vitamin E in plasma, and in particular in the LDL particles, is thought to be an important determinant of the susceptibility of LDL to oxidation. A number of investigators have studied the effect of vitamin E supplementation on oxidation status, with the levels of supplemented tocopherol ranging from 17 to $1450 \mathrm{mg} / \mathrm{d}$ (25 to $1500 \mathrm{IU} / \mathrm{d})$ (Jessup et al. 1990; Dieber-Rotheneder et al. 1991; Reaven et al. 1994; Jialal et al. 1995; Li et al. 1996). In the present study, the fish-oil and olive-oil supplements provided a total of $21 \mathrm{mg}$ total tocopherol/d of which $16 \mathrm{mg}$ was $\alpha$-tocopherol. A $9 \%$ and $13 \%$ increase in plasma and LDL $\alpha$-tocopherol occurred following olive-oil intervention. Although the level of supplementation was relatively low, it may have contributed to the increased resistance of LDL to oxidation, which was evident after 6 weeks of supplementation. In addition, an increased LDL content of oleic acid, replacing polyunsaturated fatty acids in the particle, which has been observed by other investigators (Reaven et al. 1994; Mata et al. 1996) may have been responsible in part. No significant changes in plasma or LDL $\alpha$-tocopherol were observed following fish-oil intervention and this level of supplementation $(16 \mathrm{mg} / \mathrm{d})$, which would result in a doubling in $\alpha$-tocopherol intake for the population at large, was not effective in protecting the LDL particles against the increase in oxidative susceptibility following fish-oil intervention. Other investigators have also observed that much larger doses of $\alpha$-tocopherol are needed to impact positively on LDL oxidation. For example, in a study by Jialal et al. (1995) it was found that $268 \mathrm{mg}$ (400 IU) $\alpha$-tocopherol/d was required to decrease the oxidizability of LDL and that lower doses of 40 (60 IU) or 134 (200 IU) mg/d were ineffective.
Fasting and postprandial TG responses were negatively and independently associated with the increase in platelet EPA. No significant associations with DHA changes were evident. Our results are concurrent with earlier in vitro and animal studies, which indicated that EPA is the hypotriacylglycerolaemia component of fish oil, by virtue of its impact on hepatic fatty acid oxidation and its direct impact on TG synthesis, and VLDL assembly and secretion (Willumsen et al. 1993; Berge et al. 1999). Previous studies in human subjects linking fatty acid and lipaemic changes have produced conflicting findings (Childs et al. 1990; Ågren et al. 1996; Rambjør et al. 1996; Davidson et al. 1997; Mori et al. 2000a). Further research is merited, in particular a closer examination of the individual impact of EPA and DHA supplementation on postprandial lipaemia. In addition, increased EPA status was associated with lower postprandial NEFA levels. As NEFA supply to the liver influences VLDL synthesis and circulating TG levels (Frayn, 1998), lower circulating NEFA may have contributed to the lower lipaemic response. A greater tissue oxidation of NEFA, a reduction in hormone-sensitive lipase-catalysed release of NEFA from adipocytes, or a greater tissue accumulation of NEFA produced at the capillary endothelium by the lipoprotein lipase-mediated hydrolysis of circulating $\mathrm{TG}$ may be responsible for the EPA-mediated improved NEFA status (Frayn et al. 1996). This latter lipoprotein lipase-mediated release of NEFA following the breakfast meal is thought to be responsible for the 'apparent' lack of inhibition of circulating NEFA levels post-lunch.

The findings of the present study indicate that, despite an apparent increase in LDL oxidation and LDL-chol concentration following fish-oil intervention, there is an increase in LDL density, which may counteract these proatherogenic trends. In addition, the current study may help clarify which of the $n-3$ fatty acids is responsible for the beneficial and adverse lipid changes following fish-oil intervention. However, further work is needed in order to elucidate the mechanisms by which DHA and EPA impact on lipid metabolism at the hepatic and systemic level.

\section{Acknowledgements}

We are grateful to the Biotechnology and Biological Sciences Research Council (BBSRC) for funding this project and to Pronova, Denmark, for providing us with the oil capsules.

\section{References}

Abbey M, Belling B, Noakes M, Hirata F \& Nestel PJ (1993) Oxidation of low-density lipoproteins: intra-individual variability and the effect of dietary linoleate supplementation. American Journal of Clinical Nutrition 57, 391-398.

Ågren JJ, Hänninen O, Julkunen A, Fogelholm L, Vidgren H, Schwab U, Pynnönen O \& Uusitupa M (1996) Fish diet, fish oil and docosahexaenoic acid rich oil lower fasting and postprandial plasma lipid levels. European Journal of Clinical Nutrition 50, 765-771.

Andrews B, Burnand K, Paganga G, Browse N, Rice-Evans C, Sommerville K, Leake D \& Taub N (1995) Oxidisability of 
low-density lipoproteins in patients with carotid or femoral artery atherosclerosis. Atherosclerosis 112, 77-84.

American Oil Chemists' Society (1990) Ce 8-89. Determination of Tocopherols and Tocotrienols in Vegetable Oil and Fats by HPLC, pp. 1-5: Champaign, IL: AOCS.

Austin MA, Breslow JL, Hennekens CH, Buring JE, Willett WC \& Krauss RM (1988) Low density lipoprotein subclass patterns and risk of myocardial infarction. Journal of the American Medical Association 260, 917-921.

Berge RK, Madsen L, Vaagenes H, Tronstad KJ, Göttlicher M \& Rustan AC (1999) In contrast with docosahexaenoic acid, eicosapentaenoic acid and hypolipidaemic derivatives decrease hepatic synthesis and secretion of triacylglycerol by decreased diacylglycerol acyltransferase activity and stimulation of fatty acid oxidation. Biochemistry Journal 343, 191-197.

Berliner JA, Territo MC, Sevanian A, Ramin S, Kim JA, Bamshad B, Esterson M \& Fogelman AM (1990) Minimally modified low density lipoprotein stimulates monocyte endothelial interactions. Journal of Clinical Investigation $\mathbf{8 5}$, $1260-1266$.

Bonanome A, Biasia F, DeLuca M, Munaretto G, Biffanti S, Pradella M \& Pagnan A (1996) $n-3$ Fatty acids do not enhance LDL susceptibility to oxidation in hypertriglycerolemic hemodialyzed subjects. American Journal of Clinical Nutrition 63, 261-266.

Brude IR, Drevon CA, Hjermann I, Seljeflot I, Lund-Katz S, Saarem K, Sandstad B, Solvoll K, Halvorsen B, Arnesen H \& Nenseter MS (1997) Peroxidation of LDL from combinedhyperlipidemic male smokers supplied with omega-3 fatty acids and antioxidants. Arteriosclerosis Thrombosis and Vascular Biology 17, 2576-2588.

Burr ML, Fehily AM, Gilbert JF, Rogers S, Holliday RM, Sweetnam PM, Elwood PC \& Deadman NM (1989) Effects of changes in fat, fish and fibre intakes on death and myocardial reinfarction: diet and reinfarction trial (DART). Lancet ii, $757-761$.

Buttriss J (1999) n-3 Fatty Acids and Health: Briefing Paper. London: British Nutrition Foundation.

Childs MT, King IB \& Knopp RH (1990) Divergent lipoprotein responses to fish oils with various ratios of eicosapentaenoic acid and docosahexaenoic acid. American Journal of Clinical Nutrition 52, 632-639.

Conquer JA \& Holub BJ (1997) Dietary docosahexaenoic acid as a source of eicosapentaenoic acid in vegetarians and omnivores. Lipids 32, 314-345.

Davidson MH, Maki KC, Kalkowski JA, Schaefer EJ, Torri SA \& Drennan KB (1997) Effects of docosahexaenoic acid on serum lipoproteins in patients with combined hyperlipidaemia: a randomized, double-blind placebo-controlled trial. Journal of the American College of Nutrition 16, 236-243.

DeGraaf J, Haklemmers HLM, Hectors MPC, Demacker PNM, Hendriks JCM \& Stalenhoef AFH (1991) Enhanced susceptibility to in vitro oxidation of the dense low-density lipoprotein subfraction in healthy subjects. Arteriosclerosis and Thrombosis 11, 298-306.

Dieber-Rotheneder M, Puhl H, Waeg G, Striegl G \& Esterbauer H (1991) Effect of oral supplementation with D- $\alpha$-tocopherol on the vitamin E content of human low density lipoproteins and resistance to oxidation. Journal of Lipid Research 32, $1325-1332$.

Esterbauer H, Striegl G, Puhl H \& Rotheneder M (1989) Continuous monitoring of in vitro oxidation of human low-density lipoprotein. Free Radical Research Communications 6, 6775.

Folch J, Lees M \& Sloane Stanley GH (1957) A simple method for the isolation and purification of total lipides from animal studies. Journal of Biological Chemistry 226, 497-509.
Frayn KN (1998) Non-esterified fatty acid metabolism and postprandial lipaemia. Atherosclerosis 141, S41-S46.

Frayn KN, Williams CM \& Arner P (1996) Are increased nonesterified fatty acid concentrations a risk marker for coronary heart disease and other chronic diseases? Clinical Science 90, $243-253$.

Friedewald WT \& Levy RI (1972) Estimation of the concentration of low-density lipoprotein cholesterol in plasma, without use of the preparative ultracentrifuge. Clinical Chemistry 18, 499-502.

GISSI-Prevenzione Investigators (1999) Dietary supplementation with $n-3$ polyunsaturated fatty acids and vitamin E after myocardial infarction: results of the GISSI-Prevenzione trial. Lancet 354, 447-455.

Griffin BA, Caslake MJ, Yip B, Tait GW, Packard CJ \& Shepherd J (1990) Rapid isolation of low density lipoprotein subfractions from plasma by density gradient ultracentrifugation. Atherosclerosis 83, 59-67.

Griffin BA, Freeman DJ, Tait GW, Thomson J, Caslake MJ, Packard CJ \& Shepherd J (1994) Role of plasma triglyceride in the regulation of plasma low density lipoprotein (LDL) subfractions: relative contribution of small, dense LDL to coronary heart disease risk. Atherosclerosis 106, 241-253.

Griffin BA, Minihane AM, Furlonger N, Chapman C, Murphy M, Williams D, Wright JJ \& Williams CM (1999) Inter-relationships between small, dense low-density lipoprotein (LDL), plasma triacylglycerol and LDL apoprotein B in an atherogenic lipoprotein phenotype in free-living subjects. Clinical Science 97, 269-276.

Hamilton JG \& Comai K (1988) Separation of neutral lipid, free fatty-acid and phospholipid classes by normal phase HPLC. Lipids 23, 1150-1153.

Harats D, Dabach Y, Ben-Naim M, Schwartz R, Berry EM, Stein O \& Stein Y (1991) Fish oil ingestion in smokers and nonsmokers enhances peroxidation of plasma lipoproteins. Atherosclerosis 90, 127-139.

Harris WS (1989) Fish oils and plasma lipid and lipoprotein metabolism in humans: a critical review. Journal of Lipid Research 30, 785-807.

Harris WS (1996) $n-3$ Fatty acids and lipoproteins: comparison of results from human and animal studies. Lipids 31, 243-252.

Harris WS (1997) $n$-3 Fatty acids and serum lipoproteins: human studies. American Journal of Clinical Nutrition 65, S1645-S1654

Hau MF, Smelt AHM, Bindels AJGH, Sijbrands EJG, VanderLaarse A, Onkenhout W, van Duyvenvoorde W \& Princen HMG (1996) Effects of fish oil on oxidation resistance of VLDL in hypertriglyceridaemic patients. Arteriosclerosis Thrombosis and Vascular Biology 16, 1197-1202.

Higgins S, McCarthy SN, Corridan BM, Roche HM, Wallace JMW, O'Brien NM \& Morrissey PA (2000) Measurement of free cholesterol, cholesteryl esters and cholesteryl linoleate hydroperoxide in copper-oxidised low-density lipoprotein in healthy volunteers supplemented with low dose of $n$-3 polyunsaturated fatty acids. Nutrition Research $\mathbf{2 0}$, $1091-1102$.

Holvoet P \& Collen D (1998) Oxidation of low density lipoproteins in the pathogenesis of atherosclerosis. Atherosclerosis 137, S33-S38.

Hughes GS, Ringer TV, Watts KC, DeLoof MJ, Francom SF \& Spillers CR (1990) Fish oil produces an atherogenic lipid profile in hypertensive men. Atherosclerosis 84, 229-237.

Indu M \& Ghafoorunissa (1992) n-3 Fatty acids in Indian diets comparison of the effects of precursor alpha-linolenic acid vs product long chain $n-3$ polyunsaturated fatty acids. Nutrition Research 12, 569-582.

Jessup W, Rankin SM, de Whalley CV, Hoult JRS, Scott J \& 
Leake DS (1990) $\alpha$-Tocopherol consumption during low density lipoprotein oxidation. Biochemistry Journal $\mathbf{2 6 5}$, 399-405.

Jialal I, Fuller CJ \& Huet BA (1995) The effect of $\alpha$-tocopherol supplementation on LDL-oxidation. Arteriosclerosis Thrombosis and Vascular Biology 15, 190-198.

Kendrick JS \& Higgins JA (1999) Dietary fish oils inhibit early events in the assembly of very low density lipoproteins and target apoB for degradation within the rough endoplasmic reticulum of hamster hepatocytes. Journal of Lipid Research 40, 504-514.

Li D, Devaraj S, Fuller C, Bucala R \& Jialal I (1996) Effect of alpha-tocopherol on LDL oxidation and glycation: In vitro and in vivo studies. Journal of Lipid Research 37, 1978-1986.

McNamara JR, Huang C, Massov T, Leary ET, Warnick GR, Rubins HB, Robins SJ \& Schaefer EJ (1994) Modification of the dextran- $\mathrm{Mg}^{2+}$ high-density lipoprotein cholesterol precipitation method for use with previously frozen plasma. Clinical Chemistry 40, 233-239.

Mata P, Alonso R, LopezFarre A, Ordovas JM, Lahoz C, Garces C, Caramelo C, Codoceo R, Blazquez E \& deOya M (1996) Effect of dietary fat saturation on LDL oxidation and monocyte adhesion to human endothelial cells in vitro. Arteriosclerosis Thrombosis and Vascular Biology 16, 1347-1355.

Minihane AM, Khan S, Leigh-Firbank EC, Talmud P, Wright JW, Murphy MC, Griffin BA \& Williams CM (2000a) ApoE polymorphism and fish oil supplementation in subjects with an atherogenic lipoprotein phenotype. Arteriosclerosis Thrombosis and Vascular Biology 20, 1990-1997.

Minihane AM, Khan S, Talmud PJ, Williams DL, Wright JW, Murphy MC, Griffin BA \& Williams CM (2000b) Lack of association between lipaemia and central adiposity in subjects with an atherogenic lipoprotein phenotype (ALP). International Journal of Obesity 24, 1097-1106.

Mori TA, Burke V, Puddey IB, Watts GF, O’Neal DN, Best JD \& Beilin LJ (2000a) Purified eicosapentaenoic and docosapentaenoic acids have differential effects on serum lipids and lipoproteins, LDL particle size, glucose, and insulin in mildly hyperlipidemic men. American Journal of Clinical Nutrition 71, 1085-1094.

Mori TA, Watts GF, Burke V, Hilme E, Puddey IB \& Beilin LJ $(2000 b)$ Differential effects of eicosapentaenoic acid on reactivity of the forearm microcirculation in hyperlipidemic, overweight men. Circulation 102, 1264-1269.

Nelson GJ, Schmidt PC, Bartolini GL, Kelley DS \& Kyle D (1997) The effect of dietary docosahexaenoic acid on plasma lipoproteins and tissue fatty acid composition in humans. Lipids 32, 1137-1146.

Nestel PJ, Connor WE, Reardon MR, Connor S, Wong S \& Boston R (1984) Suppression by diets rich in fish oil of very low density lipoprotein production in man. Journal of Clinical Investigation 74, 72-89.

Nilsson-Ehle P, Garfinkel A \& Schotz MC (1980) Lipolytic enzymes and plasma lipoprotein metabolism. Annual Reviews in Biochemistry 49, 667-693.

Oostenbrug GS, Mensink RP, Hardeman MR, DeVries T, Brouns F \& Hornstra G (1997) Exercise performance, red blood cell deformability, and lipid peroxidation: effects of fish oil and vitamin E. Journal of Applied Physiology 83, 746-752.

Rambjør GS, Wålen AI, Windsor SL \& Harris WS (1996) Eicosapentaenoic acid is primarily responsible for hypotriglyceridemic effect of fish oil in humans. Lipids 31, S45-S49.

Reaven P, Parthasarathy S, Grasse BJ, Miller E, Steinberg D \& Witztum JL (1993) Effects of oleate-rich and linoleate-rich diets on the susceptibility of low density lipoprotein to oxidative modification in mildly hypercholesterolemic subjects. Journal of Clinical Investigation 91, 668-676.

Reaven PD, Grasse BJ \& Tribble DL (1994) Effects of linoleateenriched and oleate-enriched diets in combination with $\alpha$-tocopherol on the susceptibility of LDL and LDL subfractions to oxidative modification in humans. Arteriosclerosis and Thrombosis 14, 557-566.

Regnstrom J, Nilsson J, Tornvall P, Landou C \& Hamsten A (1992) Susceptibility to low density lipoprotein oxidation and coronary atherosclerosis in man. Lancet 339, 1183-1186.

Sanders TAB \& Roshanai F (1983) The influence of different types of omega-3 polyunsaturated fatty acids on blood-lipids and platelet-function in healthy volunteers. Clinical Science 64, 91-99.

Steinberg D (1997) Low density lipoprotein oxidation and its pathobiological significance. Journal of Biological Chemistry 272, 20963-20966.

Suzukawa M, Abbey M, Howe PRC \& Nestel PJ (1995) Effects of fish-oil fatty acids on low-density-lipoprotein size, oxidizability, and uptake by macrophages. Journal of Lipid Research 36, 473-484.

Toshima S, Hasegawa A, Kurabayashi M, Itabe H, Takano T, Sugano J, Shimamura K, Michishita I, Suzuki T \& Nagai R (2000) Circulating oxidized low density lipoprotein levels: a biochemical marker for coronary heart disease. Arteriosclerosis Thrombosis and Vascular Biology 20, 2243-2247.

Vieira OV, Laranjinha JAN, Madeira VMC \& Almeida LM (1996) Rapid isolation of low-density lipoproteins in a concentrated fraction free from water-soluble plasma antioxidants. Journal of Lipid Research 37, 2715-2721.

Vidgren HM, Agren JJ, Schwab U, Rissanen T, Hanninen O \& Uusitupa MIJ (1997) Incorporation of $n-3$ fatty acids into plasma lipid fractions, and erythrocyte membranes and platelets during dietary supplementation with fish, fish oil, and docosahexaenoic acid-rich oil among healthy young men. Lipids 32, $697-705$.

Von Schacky C \& Weber PC (1985) Metabolism and effects on platelet function of the purified eicosapentaenoic and docosahexaenoic acids in humans. Journal of Clinical Investigation 76, 2246-2250.

Voss A, Reinhart M, Sankarappa S \& Sprecher H (1991) The metabolism of $7,10,13,16,19$-docosapentaenoic acid to 4 , $7,10,13,16,19$-docosahexaenoic acid in rat liver is independent of 4-desaturase. Journal of Biological Chemistry 266, 19995-20000.

Weis JR, Pitas RE, Wilson BD \& Rodgers GM (1991) Oxidised LDL increases cultured human endothelial cell tissue factor activity and reduces protein $\mathrm{C}$ activation. Federation of American Societies for Experimental Biology Journal 5, 2459-2465.

Willumsen N, Hexeberg S, Skorve J, Lundquist M \& Berge RK (1993) Docosahexaenoic acid shows no triglyceride-lowering effects but decreases the peroxisomal fatty acid oxidation in liver of rats. Journal of Lipid Research 34, 13-22.

Wong WH, Fisher EA \& Marsh JB (1989) Effects of eicosapentaenoic acid and docosahexaenoic acid on apolipoprotein mRNA and secretion of very low density lipoprotein in HepG2 cells. Arteriosclerosis 9, 836-841.

Zuijdgeest-van Leeuwen SD, Dagnelie PC, Rietveld T, van den Berg JWO \& Wilson JHP (1999) Incorporation and washout of orally administered $n-3$ fatty acid ethyl esters in different plasma lipid fractions. British Journal of Nutrition 82, $481-488$. 